\title{
GYNAECOLOGICAL ONCOLOGIC DISEASES AND PREGNANCY
}

D0I: $10.36740 /$ WLek202108135

\author{
Yavor Kornovski' ${ }^{1}$, Yonka Ivanova ${ }^{1}$, Stoyan Kostov ${ }^{2}$, Stanislav Slavchev ${ }^{1}$, Angel Yordanov ${ }^{3}$ \\ ${ }^{1}$ MEDICAL UNIVERSITY OF VARNA, OBSTETRICS AND GYNAECOLOGY CLINIC, ST. ANNA UNIVERSITY HOSPITAL, VARNA, BULGARIA \\ 2OBSTETRICS AND GYNAECOLOGY CLINIC, ST. ANNA UNIVERSITY HOSPITAL, VARNA, BULGARIA \\ ${ }^{3}$ DEPARTMENT OF GYNECOLOGIC ONCOLOGY, MEDICAL UNIVERSITY PLEVEN, PLEVEN, BULGARIA
}

\begin{abstract}
We review the current research literature on treatment behaviour for neoplasms of the female genital tract during pregnancy. Guidelines for clinical management of cervical cancer, ovarian tumours, and vulvar cancer are presented both regarding gynaecological oncologic treatment and obstetrics. Cervical cancer is the most common malignant tumour of the female genitalia during pregnancy due to the high incidence of this neoplasm in developing countries, including Bulgaria, on the one hand, and on the other, it affects women of reproductive age. Treatment algorithms depending on various factors - gestational age, stage of the disease, tumour lesion size, and presence of pelvic lymph node metastases, are presented. Ovarian tumours are classified into benign, borderline malignant, and malignant tumours. The latter, in turn, are divided into early and advanced stages, as well as epithelial and non-epithelial tumours, which can be detected at different stages of pregnancy.
\end{abstract}

KEY WORDS: pregnancy, malignancies of the female genitalia

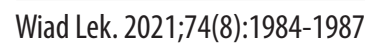

\section{INTRODUCTION}

The combination of pregnancy and a malignant tumour of gynaecological origin, although relatively rare, challenges the entire multidisciplinary team in charge. Treatment specifics of these tumours are concurrent with the realization of the purpose of pregnancy - the birth of a viable fetus without putting the mother's body at risk. In this review, the oncologic and obstetric behaviour of the following neoplasms of the female genital tract are considered:

1. Cervical cancer;

2. Ovarian tumours, divided into:

Borderline malignant tumours;

Early stages of malignant epithelial tumour;

Advanced stage of malignant epithelial tumour;

Non-epithelial ovarian tumours;

3. Vulvar cancer.

\section{THE AIM}

We review the current research literature on treatment behaviour for neoplasms of the female genital tract during pregnancy

\section{REVIEW AND DISCUSSION}

\section{CERVICAL CANCER AND PREGNANCY}

The frequency of this pathology is $1.8-4 / 100000$ pregnant women [1]. Cervical cancer is the most common malignancy of the female reproductive tract during pregnancy. The high frequency is due to the fact that in $30 \%$ of the cases, cervical cancer develops in women of reproductive age and in 3\% of these cases - during pregnancy [2].

Diagnosis of invasive cervical cancer during pregnancy is made by colposcopy and biopsy (excisional biopsy, loop biopsy). The staging is performed by MRI (nuclear magnetic imaging volumetry) and, rarely, by vaginal ultrasound [3].

The main goals of treatment behaviour in pregnant women with cervical cancer are the preservation of pregnancy, the birth of a full-term, healthy and viable fetus, and adequate treatment of the underlying disease without compromising the oncological outcome [4].

Cancer treatment and obstetric behaviour depend on lymph node status, gestational age, stage of the disease/tumour size, and last but not least, the patient's informed consent [5].

\section{TREATMENT BEHAVIOUR DEPENDING ON THE LYMPH NODE STATUS}

Sentinel lymph node dissection (SLND) is contraindicated during pregnancy as patent blue can lead to anaphylactic shock, and Tc-technetium is associated with high doses of radiation [1].

Laparoscopic pelvic lymph node dissection (LPLND) is used to determine the pelvic lymph node status. The recommendation is for LPLND to be performed up to 22 GWs due to technical difficulties in placing the trocars and access to the pelvic lymph nodes after this period [5].

In patients with lymphatic metastases (LM), the preg- 
nancy is terminated by section parva (after $12 \mathrm{GWs),} \mathrm{and}$ chemoradiotherapy (CRT) is prescribed, or by abortion during the assigned CRT (first trimester) [6].

In LM-negative patients, there are two behavioural options, depending on the length of the pregnancy. Neoadjuvant chemotherapy (NAC) is used at an earlier stage until fetal pulmonary maturity, or treatment is postponed until after delivery [7].

\section{TREATMENT BEHAVIOUR DEPENDING UPON THE STAGE OF GESTATION}

Treatment for cervical cancer differs conditional on diagnosis before and after 22 GWs.

\section{TREATMENT BEHAVIOUR CONTINGENT ON THE STAGE AND SIZE OF THE TUMOUR}

Treatment differs in IA2-IB1 stage (tumour size $<2 \mathrm{~cm}$ ), IB2 stage (tumour size 2 to $4 \mathrm{~cm}$ ), as well as in locally advanced stages CC-LACC (> IB3 stage, i.e. tumours larger than $4 \mathrm{~cm}$, as in stage IIA, B; III A, B, IV).

We will consider obstetric behaviour and cancer treatment in cases with different combinations of the above factors.

\section{CERVICAL CANCER DIAGNOSED BEFORE 22 GWS}

a) Treatment in stage IA2-IB1 (tumour size up to $2 \mathrm{~cm}$ ) $[5,8]$ :

- Staging laparoscopic pelvic lymph node dissection (LPLND) is performed.

- In the presence of lymphatic metastases (LM), the pregnancy is terminated by section parva (second trimester), and CRT is prescribed, or CRT is prescribed, and spontaneous abortion is expected (first trimester).

- In the absence of LM, fetal maturity of the fetus is awaited, and Caesarean delivery and radical hysterectomy with pelvic lymph node dissection are performed.

- Simple or radical trachelectomy can be performed 6 weeks after Caesarean section - at the patient's explicit request for organ-sparing surgery.

b) Treatment in stage IB2 (tumour size of $2-4 \mathrm{~cm}$ ) [2]:

- Staging laparoscopic pelvic lymph node dissection (LPLND) is performed.

- In the presence of lymphatic metastases (LM), the pregnancy is terminated by section parva (second trimester), and CRT is prescribed, or CRT is prescribed, and spontaneous abortion is expected (first trimester).

- In the absence of LM, neoadjuvant chemotherapy (NAC) is administered until fetal maturity is reached, followed by Caesarean delivery and radical hysterectomy with lymph node dissection.

- Radical hysterectomy with the fetus in utero is also an option in the absence of LM, with the patient's informed consent.

c) Treatment of LACC - stage IB3 (tumour size over 4 cm) - IIA [4, 6]:

- During the first trimester, CRT is prescribed, and spontaneous abortion is expected.

- During the second trimester, termination of pregnancy via section parva is recommended, and definitive CRT is prescribed.

\section{CERVICAL CANCER DIAGNOSED AFTER 22 GWS}

a) Treatment in stage IA2-IB1 (tumour size up to $2 \mathrm{~cm}$ ):

- Waiting until fetal maturity; Caesarean delivery and hysterectomy or trachelectomy (simple or radical) 6 weeks after delivery when the patient wishes organ-sparing surgery $[8,9]$.

- In case of disease progression, neoadjuvant chemotherapy (NAC) is administered until fetal maturity, followed by surgical delivery and radical hysterectomy with pelvic lymph node dissection (RH-PLND) [10].

- Termination of pregnancy by section parva and RHPLND [4];

- Laparoscopic lymph node dissection (pelvic and/or paraaortic lymphadenectomy) is technically challenging to perform; the same refers to radical hysterectomy with the fetus in utero [1].

Neoadjuvant chemotherapy (NAC) during pregnancy includes Carboplatin $\left(75 \mathrm{mg} / \mathrm{m}^{2}\right)$ and Paclitaxel $(175 \mathrm{mg} /$ $\left.\mathrm{m}^{2}\right)-3$ courses in 21-days intervals [11].

b) Treatment in stage IB2 (tumour size of 2 to $4 \mathrm{~cm}$ ):

- NAC until fetal maturity, followed by surgical delivery and radical hysterectomy with pelvic lymph node dissection (RH-PLND) [7];

- Termination of pregnancy by section parva and RHPLND [4];

c) Treatment in advanced stages - LACC (tumour size over $4 \mathrm{~cm}$ - stages IB3-IIA, IIB, IIIA, IIIB);

- NAC until fetal maturity, Caesarean delivery, and subsequent CRT [10, 11];

- Operative pregnancy termination by section parva and oncological treatment (chemoradiation) $[4,6]$.

\section{CERVICAL CANCER AND PREGNANCY. A SUMMARY}

Patients with LM should start CRT immediately, and for those without lymphatic metastases - NAC is an option until fetal maturity is reached.

If CRT is required (especially after the first trimester), evacuation of the fetus by section parva is recommended due to the risk of complications after spontaneous abortion haemorrhage, disseminated intravascular coagulation (DIC).

In the operable cervical cancer stages, pregnancy may not be maintained (with the pregnant woman's explicit consent). Radical surgery with the fetus in utero (at earlier stages of pregnancy) may be performed, or section parva - before radical surgery (in more advanced pregnancy stages).

Radical or simple trachelectomy during pregnancy is associated with a high risk of complications and should be avoided. 


\section{OVARIAN TUMOURS AND PREGNANCY}

\section{FREQUENCY AND EPIDEMIOLOGY}

Ovarian tumours are found in $0.2-8.8 \%$ of all pregnancies, and $90 \%$ of these tumours are benign. The incidence of malignant tumours is 1:12 $000-47000$ pregnancies. Germ cell tumours and epithelial tumours are the most common histotypes with borderline malignancy, and $80 \%$ of them are detected in early pregnancy [2].

\section{DIAGNOSIS}

Diagnosis is performed by ultrasound and MRI after the first trimester with low-contrast or no contrast. Tumour markers (CA 125; AFP; hCG) are not indicative during pregnancy [12].

\section{TREATMENT}

Surgical treatment is the basic treatment, and the appropriate period of pregnancy to operate is between 14 and $20 \mathrm{GWs}$ [4]. The goals of surgical treatment are: removal of the ovarian tumour, histological verification and surgical staging. The latter includes adnexectomy, omentectomy, pelvic and paraaortic lymph node dissection (up to the renal vessels), lavage and peritoneal biopsies, and contralateral ovarian biopsy. In advanced stages (with imaging evidence of ascites and/or implantation metastases), diagnostic and staging laparoscopy is recommended $[13,14]$. The histological diagnosis is based on a lasting histological result and immunohistochemistry evaluated by at least two pathologists.

Histological verification of ovarian tumours is essential for the management and prognosis of the disease. Tumours are generally classified into benign, borderline tumours, and malignant. The latter, in turn, are divided into: epithelial (low-grade serous carcinoma - LGSC; high-grade serous carcinoma - HGSC; endometrioid carcinoma; mucinous carcinoma - expansive and infiltrative type; clear cell carcinoma and Brenner's tumour), and non-epithelial. The group of non-epithelial malignant tumours consists of: genital tumours (granulosa cell tumours - juvenile and adult types; Sertoli-Leydig cell tumours (androblastoma); germ-cell tumours (dysgerminoma, immature teratoma, endodermal sinus tumour, choriocarcinoma, embryonic carcinoma); small cell carcinoma (pulmonary and hypercalcemic types).

Organ-sparing surgery (unilateral adnexectomy) and follow-up of pregnancy are admissible in [15]:

- Borderline tumours;

- Stage IA of low-grade serous carcinoma (LGSC);

- G1 and G2 endometrioid epithelial carcinoma - stage I,

- Mucinous carcinoma - expansive type, stage I;

- Granular Cell carcinoma - juvenile type, stage I;

- Germ-cell tumours in all stages.

Radical surgical treatment with the fetus in utero is required, followed by adjuvant CT, for all other histotypes and stages when complete resection is possible [15].

All staging procedures, including pelvic and paraaortic (to the renal vessels) lymph node dissection, should be performed for administering organ-sparing surgery and staging as a stage I/IA tumour [5].

Treatment in advanced stages (with imaging data on ascites and/or implantation metastases) of epithelial and germ-cell tumours $[13,14]$ :

- NAC until fetal maturity, and optimal cytoreduction after delivery;

- Mode of CT administration (Paclitaxel + Carboplatin) in the treatment of epithelial tumours;

- BEP regimen (Bleomycin, Etoposid, and Carboplatin) ii administered for germ-cell tumours;

- Targeted therapy and intraperitoneal CT are contraindicated.

\section{VULVAR CARCINOMA AND PREGNANCY}

Treatment regardless of gestational age:

a) Wide local excision, radical vulvectomy/hemivulvectomy [2];

Radicality requires a resection margin of at least $2 \mathrm{~cm}$ from the tumour.

b) Inguinal lymph node dissection (ILND) is indicated for tumours larger than $2 \mathrm{~cm}$. It can be performed unilaterally in laterally located lesions [4].

c) In the presence of lymphatic metastases (LM), there are two treatment options $[2,4,5]$ :

- During the first and second trimesters: termination of pregnancy (by prostaglandins) and administration of radiotherapy;

- In the third trimester: Caesarean delivery after fetal maturity and administration of radiotherapy;

d) Delayed radiotherapy should not be postponed for more than $6-8$ weeks [16].

\section{REFERENCES}

1. Morice $P$, Narducci F, Mathevet $P$ et al. French recommendations on the management of invasive cervical cancer during pregnancy. Int J Gynecol Cancer. 2009 Dec;19(9):1638-41.

2. Han SN, Kesic VI, Van Calsteren K, et al. Cancer in pregnancy: a survey of current clinical practice. Eur J Obstet Gynecol Reprod Biol. 2013 Mar; 167(1):18-23.

3. Kanal E, Barkovich AJ, Bell C, Borgstede JP, et al. ACR guidance document for safe MR practices: 2007. AJR Am J Roentgenol. 2007 Jun; 188(6): 1447-74

4. Amant F, Van Calsteren K, Halaska MJ et al. Gynecologic cancers in pregnancy: guidelines of an international consensus meeting. Int J Gynecol Cancer. 2009 May;19 Suppl 1:S1-12.

5. Morice $P$, Uzan C, Gouy S, et al. Gynaecological cancers in pregnancy. Lancet. 2012 Feb 11; 379 (9815): 558-69.

6. Sood AK, Sorosky Jl, Mayr N, et al. Radiotherapeutic management of cervical carcinoma that complicates pregnancy. Cancer. 1997 Sep 15; 80(6): 1073-8.

7. Rydzewska L, Tierney J, Vale CL et al. Neoadjuvant chemotherapy plus surgery versus surgery for cervical cancer. Cochrane Database Syst Rev. 2012 Dec 12; 12(12): CD007406.

8. Schmeler KM, Frumovitz M, Ramirez PT. Conservative management of early stage cervical cancer: is there a role for less radical surgery? Gynecol Oncol. 2011 Mar; 120(3): 321-5. 
9. Rob L, Skapa P, Robova H. Fertility-sparing surgery in patients with cervical cancer. Lancet Oncol. 2011 Feb; 12(2): 192-200.

10. Zagouri F, Sergentanis TN, Chrysikos D et al. Platinum derivatives during pregnancy in cervical cancer: a systematic review and meta-analysis. Obstet Gynecol. 2013 Feb; 121(2 Pt 1): 337-43.

11. Cardonick E, Bhat A, Gilmandyar D, et al. Maternal and fetal outcomes of taxane chemotherapy in breast and ovarian cancer during pregnancy: case series and review of the literature. Ann Oncol. 2012 Dec;23(12):3016-3023.

12. Telischak NA, Yeh BM, Joe BN et al. MRI of adnexal masses in pregnancy. AJR Am J Roentgenol. 2008 Aug;191(2):364-70.

13. Zagouri F, Sergentanis TN, Chrysikos D et al. Taxanes for ovarian cancer during pregnancy: a systematic review. Oncology. 2012; 83(4): 234-8.

14. Motegi M, Takakura S, Takano $\mathrm{H}$, et al. Adjuvant chemotherapy in a pregnant woman with endodermal sinus tumor of the ovary. Obstet Gynecol. 2007 Feb;109(2 Pt2):537-40.

15. Zhao XY, Huang HF, Lian LJ, et al. Ovarian cancer in pregnancy: a clinicopathologic analysis of 22 cases and review of the literature. Int J Gynecol Cancer. 2006 Jan-Feb;16(1):8-15.

16. Alexander A, Harris RM, Grossman D et al. Vulvar melanoma: diffuse melanosis and metastasis to the placenta. J Am Acad Dermatol. 2004 Feb; 50(2): 293-8.

\section{ORCID and contributionship:}

Yavor Kornovski: 0000-0003-1795-4428 A,D,F

Yonka Ivanova: 0000-0001-5518-5186 ${ }^{B}$

Stoyan Kostov: 0000-0002-5279-3095 B,F

Angel Danchev Yordanov: 0000-0002-7719-382X E-F

Stanislav Slavchev: 0000-0003-4830-6159 ${ }^{\mathrm{E}-\mathrm{F}}$

\section{Acknowledgements:}

Authors want to thank Georgi Kostov for his technical support and Miglena Nevyanova Drincheva for her beautiful artwork.

\section{Conflict of interest:}

The Authors declare no conflict of interest.

\section{CORRESPONDING AUTHOR Angel Danchev Yordanov}

Department of Gynecologic Oncology,

Medical University Pleven, Bulgaria

e-mail: angel.jordanov@gmail.com

Received: 03.04.2021

Accepted: 14.06 .2021

A - Work concept and design, B - Data collection and analysis, C - Responsibility for statistical analysis,

D-Writing the article, $\mathbf{E}$-Critical review, $\mathbf{F}$ - Final approval of the article 